\begin{tabular}{|l|l|l|}
\hline \multicolumn{2}{|c|}{ PublisherInfo } \\
\hline \hline PublisherName & $:$ & BioMed Central \\
\hline \hline PublisherLocation & $:$ & London \\
\hline \hline PublisherImprintName & $:$ & BioMed Central \\
\hline \hline
\end{tabular}

\title{
Association of MHC Class II and CD40
}

\begin{tabular}{||l|l|l||}
\hline \multicolumn{2}{|c||}{ ArticleInfo } \\
\hline \hline ArticleID & $:$ & 207 \\
\hline \hline ArticleDOI & $:$ & $10.1186 /$ ar-2000-66781 \\
\hline \hline ArticleCitationID & $:$ & 66781 \\
\hline \hline ArticleSequenceNumber & $:$ & 164 \\
\hline \hline ArticleCategory & $:$ & Paper Report \\
\hline ArticleFirstPage & $:$ & 1 \\
\hline \hline ArticleLastPage & $:$ & 4 \\
\hline \hline & $:$ & RegistrationDate : 2000-2-8 \\
ArticleHistory & $:$ & OnlineDate \\
\hline \hline ArticleCopyright $2000-2-8$ \\
\hline \hline ArticleGrants & $:$ & Current Science Ltd2000 \\
\hline \hline ArticleContext & $:$ & \\
\hline \hline
\end{tabular}


Aff1 United Medical and Dental Schools of Guy's and St Thomas' Hospital, London

\section{Keywords}

B cell, CD40, CD40 ligand, MHC class II, signal transduction

\section{Context}

CD40 and MHC class II are intimately involved in the cross-talk between T and B cells. CD40 is a membrane glycoprotein expressed by B cells, monocytes and dendritic cells and is an important costimulatory molecule. The ligation of MHC class II/peptide by the T cell receptor (TCR) is accompanied by CD40 binding CD40 ligand (CD40L) expressed by activated CD ${ }^{+} \mathrm{T}$ cells. This interaction both influences the processes of thymic selection and peripheral tolerance and regulates humoral immunity. To determine whether CD40 and MHC class II molecules are physically associated on the B cell surface and whether activation of the B cell is important. The interaction of the MHC class II/CD40 complex with the cytoskeleton was also investigated.

\section{Significant findings}

Immunoprecipitation of Raji, LAD and JY cell lysates with CD40 mAbs resulted in additional bands at 30 and $35 \mathrm{kDa}$ (migration pattern of MHC class II a and ? chains). These were not evident in lysates of the MHC class II deficient RM3 cell line. The bands were absent from Ramos cell lysate unless the cells were stimulated with either CD40 or HLA-DR. The 30 and $35 \mathrm{kDa}$ bands could also be coprecipitated using anti-CD23 mAb. Western blotting with anti-DR mAb confirmed that the 30 and 35 $\mathrm{kDa}$ bands were of MHC class II origin. HLA-DRa was, however, absent from lysates immunoprecipitated with surface IgM, demonstrating the specificity of the association. Daudi cells, used to exclude a role for EBV LMP1, were also shown to have co-precipitation of the HLA-DRa with CD40. Complementary experiments where HLA-DRa antibody was used to immunoprecipitate lysates revealed the co-precipitation of CD40 molecules. Anti-CD40 mAb did not co-precipitate MHC class I. To exclude the possibility that coprecipitation was an artefact of B cell transformation, normal human tonsillar B cells were studied and showed the same co-precipitation patterns.

Crosslinking cell surface molecules resulted in the association of over $70 \%$ of CD40 and $2-4 \%$ of HLA-DR molecules with the NP-40 insoluble cell matrix. In contrast, only $0.4 \%$ HLA-DR molecules 
were associated with matrix in the absence of CD40 crosslinking. The binding of SEA to HLA-DR did not affect the precipitation patterns.

\section{Comments}

The CD40/CD40L interaction is an attractive target for immunotherapy in autoimmune diseases due to its role in $\mathrm{B}$ cell regulation and the induction of peripheral $\mathrm{T}$ cell tolerance. This study demonstrates interaction between HLA-DR and CD40 on the B cell surface and suggests that activation may provide a signal from this complex to the cellular matrix. A small fraction of the total surface HLA-DR molecules are involved in these complexes and it is unclear how they are selected or what function they may perform in this complex. The experiments investigated only HLA-DR molecules, so it is possible that HLA-DQ and -DP molecules and, even the polymorphic variants of HLA-DR, may behave differently.

\section{Methods}

Experiments used multiple B-cell lines: Raji, RM3 (MHC class II deficient derivative of the Raji line), two Epstein-Barr virus (EBV)-transformed B-cell lines (LAD and JY), EBV-negative Burkitt's lymphoma Ramos cells (germinal centre B cells), and Daudi cells, which are EBV-transformed but do not express the EBV-encoded latent infection membrane protein (LMP)-1. In addition, B cells from normal human tonsils were examined.

Immunoprecipitation experiments using biotin-labelled cells and two anti-CD40 monoclonal antibodies (mAbs) were performed. Co-precipitation experiments were also performed with mAb specific for CD23, which is known to physically associate with HLA-DR. Western blotting with antiHLA-DR mAb was used to analyse immunoprecipitates obtained with CD40, CD23 mAbs or surface immunoglobulin M. Daudi cells were used to exclude the possibility of EBV-encoded LMP1 causing aggregation of CD40 and HLA-DR. Complementary experiments were performed using HLA-DR for immunoprecipitation and CD40 mAb in western blots.

To assess whether crosslinking of CD40 triggered association of CD40 and HLA-DR with the cytoskeleton, murine anti-CD40 antibodies, followed by anti-mouse IgG, were used to crosslink CD40 molecules on the cell surface. Fluorescein isothiocyanate (FITC)-labelled anti-DR antibodies were used to label DR molecules and the labelled cells were lysed with NP-40. Flow cytometry was used to assess the percentage of HLA-DR molecules associated with the NP-40 insoluble cell matrix. Finally, using

Raji cells, the interaction of MHC class II with the ligand staphylococcal enterotoxin A (SEA) was used to determine whether ligand binding influenced the formation of the CD40/MHC class II complex. 


\section{References}

1. Leveille C, Chandad F, Al-Daccak R, Mourad W: CD40 associates with the MHC class II molecules on human B cells. Eur J Immunol. 2000, 29: 3516-3526.

This PDF file was created after publication. 